\title{
On the relationship between gas and dust in 15 comets: an application to Comet 103P/Hartley 2 target of the NASA EPOXI mission of opportunity
}

\author{
G. C. Sanzovo ${ }^{1}$, D. Trevisan Sanzovo ${ }^{1}$, and A.A. de Almeida ${ }^{2}$ \\ ${ }^{1}$ Department of Physics, State University of Londrina, Londrina, PR, Brazil \\ email: gsanzovo@uel.br \\ ${ }^{2}$ Department of Astronomy, University of São Paulo, São Paulo, SP, Brazil \\ email: amaury@astro.iag.usp.br
}

\begin{abstract}
After the success of Deep Impact mission to hit the nucleus of Comet 9P/Tempel 1 with an impactor, the concerns are turned now to the possible reutilization of this dormant flyby spacecraft in the study of another comet, for only about $10 \%$ of the cost of the original mission. Comet 103P/Hartley 2 on UT 2010 October 11 is the most attractive target in terms of available fuel at rendezvous and arrival time at the comet. In addition, the comet has a low inclination so that major orbital plane changes in the spacecraft trajectory are unnecessary. In an effort to provide information concerning the planning of this new NASA EPOXI space mission of opportunity, we use in this work, visual magnitudes measurements available from International Comet Quarterly (ICQ) to obtain, applying the Semi-Empirical Method of Visual Magnitudes - SEMVM (de Almeida, Singh, \& Huebner 1997), the water production rates (in molecules/s) related to its perihelion passage of 1997 . When associated to the water vaporization theory of Delsemme (1982), these rates allowed the acquisition of the minimum dimension for the effective nuclear radius of the comet. The water production rates were then converted into gas production rates (in $\mathrm{g} / \mathrm{s}$ ) so that, with the help of the strong correlation between gas and dust found for 12 periodic comets and 3 non-period comets (Trevisan Sanzovo 2006), we obtained the dust loss rates (in $\mathrm{g} / \mathrm{s}$ ), its behavior with the heliocentric distance and the dust-to-gas ratios in this physically attractive rendezvous target-comet to Deep Impact spacecraft at a closest approach of $700 \mathrm{~km}$.
\end{abstract}

Keywords. Gas release rates - Dust release rates - Dust-to-gas ratios - Short-period comets Comet 103P/Hartley 2

\section{Introduction}

Comet 103P/Hartley 2 was discovered on 1984 November 28 in Australia, by Malcolm Hartley, having estimated visual magnitude 17-18 (Hartley 1984). For its 1997 return, ICQ makes available a set of 857 visual magnitudes measurements, obtained by several observers, taken between 1997 March 3.16 ( $\mathrm{r}=2.803$ AU) and 1998 May 19.48 ( $\mathrm{r}=2.104$ AU). In the present work, we apply the Semi-Empirical Method of Visual Magnitudes (SEMVM) to this visual magnitude data to find water, and hence gas production rates. Combining our derived water release rates with the vaporization theory of Delsemme (1982), provided the determination of the comet's nuclear dimensions and active areas. We also used the gas-to-dust correlation found by Trevisan Sanzovo (2006) for 12 Jupiter Family (JF) comets with the purpose to estimate the corresponding dust loss rates for Comet 103P/Hartley 2. 


\section{Theoretical Considerations}

\subsection{The Semi-Empirical Method of Visual Magnitudes (SEMVM) and the Gas-to-Dust correlation}

If $\mathrm{m}_{v^{\prime}}$ is the total visual magnitude observed from the coma of a comet, reduced to the standard diameter of $6.78 \mathrm{~cm}$ when the observer is placed at a standard geocentric distance $\Delta=1 \mathrm{AU}$, (Morris (1973)) and the comet at a heliocentric distance $\mathrm{r}$ (in AU), the water production rate (in molecules/s) is given by (de Almeida, Singh, \& Huebner 1997; Sanzovo et al. 2001)

$$
Q\left(H_{2} O\right)=\left\{\frac{r^{2} \cdot 10^{\left[0.4\left(-26.8-m_{v^{\prime}}\right)\right]}-p \cdot R_{N}^{2} \cdot \Phi_{N}}{R \cdot l_{r} \cdot[1+\delta(r, \theta)]}\right\}^{0.825},
$$

where $\mathrm{p}=\mathrm{p}(\lambda)$ is the geometric visual albedo of the comet's nucleus with radius $\mathrm{R}_{N}$, and the other parameters of Equation (2.1) and framework of SEMVM are reported in details elsewhere (Sanzovo et al. 1996, and de Almeida, Singh, \& Huebner 1997). Once the water production rates are obtained, its conversion into gas loss rates can be accomplished, considering a gaseous mixture of $\sim 77 \% \mathrm{H}_{2} \mathrm{O}, \sim 13 \% \mathrm{CO}$, and $\sim 10 \%$ of other molecular species with average molecular weight $\sim 30$ amu (Sanzovo et al. 1996; de Almeida, Singh, \& Huebner 1997). Active surface areas and nuclear dimensions were inferred combining SEMVM and Delsemme's theory (Delsemme 1982). In view of lack of information in literature about continuum observations refering to Comet 103P/Hartley 2 , we used for the estimate of the dust loss rates, $\mathrm{q}_{d}$, the gas-to-dust correlation found by Trevisan Sanzovo (2006) for 12 periodic comets determined for $\lambda=4845$ and $4770 \AA$, and dust particle density $\rho_{d}=0.5 \mathrm{~g} / \mathrm{cm}^{3}$. The strong gas-to-dust correlation is given by $\log \left(q_{g}\right)=(2.796 \pm 0.161)+(0.599 \pm 0.025) \times \log \left(q_{d}\right)$. Trevisan Sanzovo (2006) also provide other dust-to-gas correlation $\left[\log \left(q_{g}\right)=(-0.200 \pm 0.203)+(1.067 \pm 0.031) \times \log \left(q_{d}\right)\right]$ valid for Comets C/Hale-Bopp, C/Hyakutake, C/Levy, and also including 1P/Halley. The use of the gas-to-dust correlation for our JF cometary sample made possible the estimate of the dust loss rates, as well as the dust-to-gas ratios for the 1997 return of Comet 103P/Hartley 2.

\section{Results and Discussion}

Our analysis is based on Figure 1 and Table I, which summarize main results. There, in addition to the nomenclature, the first column shows the perihelion passages corresponding to the gas and dust analysis quoted between parenthesis and brackets, respectively. In column 2, we have the orbital period (in years) of the objects, while the nuclear radius (in $\mathrm{km}$ ), the fraction of active area (in \%), and the active surface area (in $\left(\mathrm{km}^{2}\right)$ is shown in column 3 of the same table.

\subsection{Nuclear Dimensions and Masses}

We fixed the active surface area in $20 \%$ for the nuclear hemisphere lit by the sun, and the water production rates obtained through the application of SEMVM were combined with the vaporization rates of Delsemme (1982), resulting in an effective nuclear radius of $\sim$ $1.8 \mathrm{~km}$ for Comet $103 \mathrm{P} /$ Hartley 2 . If $\mathrm{f}_{A A}=1.0$, the water vaporization and production rates will be compatible with a minimum nuclear radius of $\sim 0.8 \mathrm{~km}$. We verify therefore, that Comet 103P/Hartley 2 has, amongst the JF comets of the sample, about the same dimension of Comet $21 \mathrm{P} / \mathrm{GZ}$, whose effective nuclear radius is $\sim 1.7 \mathrm{~km}$. For an activity of $100 \%$, Comet 103P/Hartley 2 has about the same dimension of Comet C/Hyakutake (see Table I). We also make an estimate of the nuclear masses which are shown in column 
Table 1. Gas and dust properties for Comet 103P/Hartley 2 and other 15 comets.

\begin{tabular}{|c|c|c|c|c|c|c|c|c|c|c|}
\hline Com et & $\begin{array}{c}\mathbf{P} \\
(\text { years })\end{array}$ & $\begin{array}{l}\mathbf{R}_{N}-\mathbf{f}_{A A}-\mathbf{A}_{A} \\
\left(\mathbf{k} \mathbf{m}-\mathbf{\%}-\mathbf{k ~ m}^{2}\right)\end{array}$ & $\begin{array}{c}\mathbf{M}^{(a)} \\
(\mathrm{g})\end{array}$ & $\begin{array}{c}\mathrm{q} g \\
(\mathrm{~g} / \mathrm{s})\end{array}$ & $\begin{array}{c}\mathrm{q}_{d} \\
(\mathrm{~g} / \mathrm{s})\end{array}$ & $\begin{array}{c}\mathbf{Q}_{T}^{(b)} \\
(\mathbf{k g} / \mathbf{s})\end{array}$ & & $\chi$ & $\begin{array}{l}\mathbf{R}_{N}^{(c)} \\
(\mathbf{k} \mathbf{m})\end{array}$ & References \\
\hline $\begin{array}{l}\text { 1P/H alley } \\
(1986) ;[1986]\end{array}$ & $\sim 76$ & $\begin{array}{l}1.5-100-14 \\
5.0-10-157\end{array}$ & $2.6(17)$ & $\begin{array}{l}\propto \mathrm{r}-4.74 * \\
\propto \mathrm{r}-3.15 \diamond\end{array}$ & $\propto \mathrm{r}-3.18 \bullet$ & $\begin{array}{l}\sim 2670^{*} \\
\sim 6100^{\circ}\end{array}$ & 0.18 & -2.17 & 5.0 & W E A 97 \\
\hline $\begin{array}{l}9 \mathrm{P} / \mathrm{Tempel} 1 \\
(1972,83,89,94, \\
00,05) ;[1983]\end{array}$ & $\sim 5.5$ & $\begin{array}{l}1.5-100-14 \\
2.0-10-25\end{array}$ & $1.7(16)$ & $\begin{array}{l}\propto r-8.79 * \\
\propto r-6.47 \diamond\end{array}$ & $\propto r^{-4.21}$ & $\sim 340^{*}$ & 0.02 & -0.38 & 2.3 & T A N 00 \\
\hline $\begin{array}{l}10 \mathrm{P} / \text { Tempel } 2 \\
(1983,88,94,99) ; \\
{[1983,88,99]}\end{array}$ & $\sim 5.5$ & $\begin{array}{l}1.2-100-9 \\
2.7-20-46\end{array}$ & $4.1(16)$ & $\begin{array}{l}\propto r-7.56 * \\
\propto r-7.62 \diamond\end{array}$ & $\propto r-6.02 \bullet$ & $\begin{array}{l}\sim 176^{*} \\
\sim 532^{\diamond}\end{array}$ & 0.01 & -0.47 & 2.9 & TAN 00 \\
\hline $\begin{array}{l}21 \mathrm{P} / \mathrm{G} \mathrm{Z} \\
(1985,98) ;\left[\begin{array}{l}1985 \\
\text { (1985 }\end{array}\right.\end{array}$ & $\sim 6.6$ & $\begin{array}{l}0.9-100-5 \\
1.7-20-18\end{array}$ & $1.0(16)$ & $\begin{array}{l}\propto r-4.75 * \\
\propto r-3.23 \diamond\end{array}$ & $\propto r-1.69 \bullet$ & $\begin{array}{l}\sim 244^{*} \\
\sim 247^{\diamond}\end{array}$ & 0.08 & -0.36 & 1.0 & TAN 00 \\
\hline $\begin{array}{l}22 \mathrm{P} / \mathrm{K} \text { op ff } \\
(1983,90,96) ;[1983]\end{array}$ & $\sim 6.5$ & $\begin{array}{l}1.9-100-23 \\
4.3-20-116\end{array}$ & $1.7(17)$ & $\begin{array}{l}\propto \mathrm{r}-5.85 * \\
\propto r-4.34 \diamond\end{array}$ & $\propto r-3.60 \bullet$ & $\begin{array}{l}\sim 895^{*} \\
\sim 714^{\diamond}\end{array}$ & 0.06 & -0.34 & 1.8 & TA N 00 \\
\hline $\begin{array}{l}24 \mathrm{P} / \mathrm{Sch} \text { aum asse } \\
(1984,93) ;[1984]\end{array}$ & $\sim 8.2$ & $\begin{array}{c}0.4-100-1 \\
0.9-20-5\end{array}$ & $1.5(15)$ & $\begin{array}{l}\propto r-12.42 * \\
\propto r-8.20 \diamond\end{array}$ & - & $\begin{array}{l}\geqslant 23^{*} \\
\geqslant 82^{\diamond}\end{array}$ & 0.03 & -0.85 & 0.8 & TAN 00 \\
\hline $\begin{array}{l}26 \mathrm{P} / \mathrm{G} \mathrm{S} \\
(1982,87,92) \\
\quad[1977,82]\end{array}$ & $\sim 5.1$ & $\begin{array}{l}0.3-100-1 \\
1.0-10-6\end{array}$ & $2.1(15)$ & $\begin{array}{l}\propto r-7.56 * \\
\propto r-5.37 \diamond\end{array}$ & $\propto r-7.27 \diamond$ & $\sim 19$ & 0.02 & -0.25 & 1.3 & T A N 00 \\
\hline $\begin{array}{l}46 \mathrm{P} / \mathrm{W} \text { irtanen } \\
(1986,91,97) ; \\
{[1991,97]}\end{array}$ & $\sim 5.5$ & $\begin{array}{l}0.7-100-3 \\
1.5-20-14\end{array}$ & $7.1(15)$ & $\begin{array}{l}\propto r-8.06 * \\
\propto r-6.28 \diamond\end{array}$ & $\propto r-4.94 \bullet$ & $\begin{array}{l}\sim 80^{*} \\
\sim 163^{\diamond}\end{array}$ & 0.02 & -0.08 & 0.7 & TAN 00 \\
\hline $\begin{array}{l}62 \mathrm{P} / \mathrm{Tsuchinshan} 1 \\
(1985,98) ;[1985]\end{array}$ & $\sim 6.6$ & $\begin{array}{l}0.7-100-3 \\
1.5-20-16\end{array}$ & $7.1(15)$ & $\propto r-10.08 \bullet$ & $\propto r-8.67 \bullet$ & $\sim 64^{\bullet}$ & 0.03 & -0.14 & 0.8 & T A N 00 \\
\hline $\begin{array}{l}67 \mathrm{P} / \mathrm{CG} \\
(1982,96) ;[1982,96]\end{array}$ & $\sim 6.6$ & $\begin{array}{l}0.7-100-3 \\
2.1-10-28\end{array}$ & $1.9(16)$ & $\begin{array}{l}\propto r-4.46 * \\
\propto r-4.29 \diamond\end{array}$ & $\propto r-4.11 \bullet$ & $\begin{array}{l}\sim 75^{*} \\
\sim 132^{\diamond}\end{array}$ & 0.04 & -1.00 & 2.5 & TAN 00 \\
\hline $\begin{array}{l}81 \mathrm{P} / \mathrm{W} \text { ild } 2 \\
(1990,97,030 \\
{[1978,84,97]}\end{array}$ & $\sim 6.4$ & $\begin{array}{c}1.5-100-14 \\
3.9-20-96\end{array}$ & $2.5(16)$ & $\begin{array}{l}\propto r-5.22 * \\
\propto r-6.59 \diamond\end{array}$ & $\propto r-2.77 \bullet$ & $\begin{array}{l}\sim 868^{*} \\
\sim 690^{\circ}\end{array}$ & 0.07 & -1.15 & 2.2 & TAN 00 \\
\hline $\begin{array}{l}\text { C/Hyakutake } \\
(1996) ;[1996]\end{array}$ & $>200$ & $\begin{array}{l}1.0-100-6 \\
2.4-20-36\end{array}$ & $2.9(16)$ & $\begin{array}{l}\propto r-2.73 * \\
\propto r-2.99 \diamond\end{array}$ & $\propto r-1.85 *$ & $\sim 3340^{*}$ & 0.15 & -1.47 & 2.4 & L IS 99 \\
\hline $\begin{array}{l}\text { C / Levy } \\
(1990) ;\left[\begin{array}{l}1990 \\
(1990\end{array}\right.\end{array}$ & $>200$ & $\begin{array}{c}1.6-100-16 \\
3.4-10-73\end{array}$ & $8.2(16)$ & $\begin{array}{l}\propto r-2.80 * \\
\propto r-4.01 \diamond\end{array}$ & $\propto r-2.10 \bullet$ & $\begin{array}{l}\sim 12240^{*} \\
\sim 9560^{\diamond}\end{array}$ & 0.19 & -1.53 & $2.4-3.4$ & S C H 91 \\
\hline $\begin{array}{l}\text { C / H a le-B op p } \\
(1997) ;[1997]\end{array}$ & $>200$ & $\begin{array}{c}16.8-100-1774 \\
26.7-40-4480\end{array}$ & $4.0(19)$ & $\begin{array}{l}\propto \mathrm{r}-3.53 * \\
\propto \mathrm{r}-3.75 \diamond\end{array}$ & $\propto \mathrm{r}-1.00 \bullet$ & $\begin{array}{l}\sim 47200^{*} \\
\sim 50500^{\circ}\end{array}$ & 0.28 & -27.68 & 30.0 & FER 03 \\
\hline $\begin{array}{l}85 \mathrm{P} / \mathrm{B} \text { oethin } \\
(1986)\end{array}$ & $\sim 11.2$ & $\begin{array}{l}0.8-100-4 \\
1.9-20-23\end{array}$ & $1.4(16)$ & $\begin{array}{l}\propto \mathrm{r}-5.21 * \\
\propto \mathrm{r}-5.34 \diamond\end{array}$ & $\begin{array}{l}\propto \mathrm{r}-6.90 \bullet \\
\propto \mathrm{r}-7.08 \diamond\end{array}$ & $\begin{array}{l}\sim 419.5^{*} \\
\sim 388.5^{\diamond}\end{array}$ & 0.10 & -0.40 & 0.7 & A HE 95 \\
\hline $\begin{array}{l}103 \mathrm{P} / \mathrm{Hartley} 2 \\
(1997)\end{array}$ & $\sim 6.4$ & $\begin{array}{l}0.8-100-4 \\
1.8-20-20\end{array}$ & $1.2(16)$ & $\begin{array}{l}\propto \mathrm{r}-7.42 * \\
\propto \mathrm{r}-8.81 \diamond\end{array}$ & $\begin{array}{l}\propto \mathrm{r}-9.83 \bullet \\
\propto \mathrm{r}-5.14 \diamond\end{array}$ & $\begin{array}{l}\sim 51.5^{*} \\
\sim 52.3^{\diamond}\end{array}$ & 0.02 & -0.25 & $\begin{array}{c}0.7 \\
0.57\end{array}$ & $\begin{array}{l}\text { G R O } 04 \\
\text { L IS } 09\end{array}$ \\
\hline
\end{tabular}

(a) $2.6(17)$ means $2.6 \times 10^{17} ;(b)$ For $r=1.6 \mathrm{AU} ;(c)$ Data from ${ }^{\text {D }}$ Literature for comparison; $*$ for pre-perihelic phase; $\diamond$ for post-perihelic phase, and $\bullet$ for pre- and post-perihelic phases; WEA97 = Weaver et al. $(1997)$; TAN00 = Tancredi et al. $(2000)$; LIS $99=\mathrm{Lisse}$ et al. (1999): SCH91 = Schleicher et al. (1991): A HE95 = A'Hearn et al. (1995): FER03= Fernández et al. (2003); GRO04 = Groussin et al. $(2004)$, and LIS09= Lisse et al. (2009).

4 of Table I. For this calculation, we considered a spherical nucleus and adopted a mean nuclear density $\rho_{N}=0.5 \mathrm{~g} / \mathrm{cm}$. With this procedure we verify that Hartley 2 is a JF comet with intermediary mass $\left(\mathrm{M} \sim 1.2 \times 10^{16} \mathrm{~g}\right)$, being comparable to $21 \mathrm{P} / \mathrm{GZ}$, and $\sim 22$ times less massive than Comet Kopff.

\subsection{Gas, Dust, Dust-to-Gas Ratios and Productivity}

The application of SEMVM to Comet 103P/Hartley 2 yield average gas production rates (in $\mathrm{g} / \mathrm{s}$ ) which vary with the heliocentric distance according with the power-law $\mathrm{q}_{g}=(1.572 \pm 0.045) \times 10^{6} \cdot r^{-7.43( \pm 0.16)}$ in the pre-perihelion phase interval $2.803 \leqslant \mathrm{r}(\mathrm{AU})$ $\leqslant 1.032$, and $\mathrm{q}_{g}=(1.328 \pm 0.221) \times 10^{6} \cdot \mathrm{r}^{-8.81( \pm 1.00)}$ in the post-perihelion phase comprehended between $\mathrm{r}=1.032$ and $2.104 \mathrm{AU}$. We find that, at perihelion ( $\mathrm{r}=1.032 \mathrm{AU})$, Comet 103P/Hartley 2 lost gas at an average rate of $\sim 1.2 \times 10^{6} \mathrm{~g} / \mathrm{s}$, with a maximum of gas production rate estimated as $\mathrm{q}_{g} \sim 3.5 \times 10^{6} \mathrm{~g} / \mathrm{s}$. At perihelion and $\mathrm{r}=1.04 \mathrm{AU}$, A'Hearn et al. (1995), Crovisier et al. (1999) and Colangeli et al. (1999) found $\mathrm{Q}\left(\mathrm{H}_{2} \mathrm{O}\right)$ $=3.0 \times 10^{28}, 1.24 \times 10^{28}$ and $3.1 \times 10^{28}$ molecules $/ \mathrm{s}$, which corresponds to $\mathrm{q}_{g}=1.03 \times 10^{6}$, $4.24 \times 10^{5}$ and $1.06 \times 10^{6} \mathrm{~g} / \mathrm{s}$, respectively. Hence, our results are in reasonable agreement with those authors. Inspection of Table I show that Comet 103P/Hartley 2 is nearly two orders of magnitude less active than Comet $1 \mathrm{P} /$ Halley, and about three orders of magnitude less productive than Comets $\mathrm{C} /$ Hyakutake and C/Hale-Bopp. Besides the orbital period, dimensions and nuclear masses, Table I also presents in columns 5,6 , and 8 the 
dependencies with heliocentric distance of the gas and dust loss rates, and dust-togas mass ratios, respectively. In the last two columns of the same Table I we include nuclear radii and respective references found in literature, for comparison. The total mass loss rates, $\mathrm{Q}_{T}$ (in $\mathrm{kg} / \mathrm{s}$ ), in the form of gas and dust, are shown in column 7 of the Table I, being obtained fixing $\mathrm{r}=1.6 \mathrm{AU}$. The results indicate that Comets 22P/Kopff and 81P/Wild 2 in 1996 and 1997 apparitions, respectively, lost $\sim 17$ times more mass than Comet 103P/Hartley 2 which, in the pre-perihelic phase was more productive than Comets 24P/Schaumasse and 26P/GS. Comparing dust and gas mass release rates obtained in this work, we conclude that Comet Hartley 2 has predominantly $0.02<\chi<0.25$, being classified as belonging to the family of comets with intermediate dust-to-gas mass ratios (Sanzovo et al. 1996).

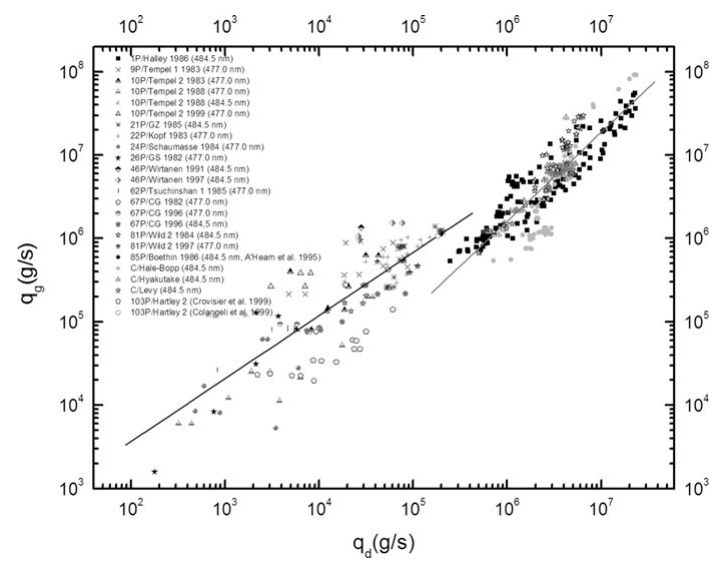

Figure 1. Correlation between gas and dust mass rates in 15 comets (after Trevisan Sanzovo 2006.)

\section{Acknowledgements}

This work was partially supported by FAPESP (São Paulo, SP, Brazil) under grant No. 09/50626-8. GCS is grateful to PROPPG-UEL (Londrina, PR, Brazil) for financial help.

\section{References}

A'Hearn, M. F., Millis, R. L., Schleicher D. G. et al. 1995, Icarus 118, 223

de Almeida, A. A., Singh, P. D., \& Huebner, W. F. 1997, Planet. Space Sci. 45, 681 A\& A 45, 681

Colangeli, L., Epifani, E., Brucato, J. R. et al. 1999, A\&\& 343, L87

Crovisier, J., Encrenaz, Th., Lellouch, E. et al. 1999, ESASP 427, 161

Delsemme, A. H. 1982, in: L. L. Wilkening (ed.) Comets University of Arizona Press, Tucson, p. 85

Groussin, O., Lamy, P., Jorda, L. et al. 2004, A\& A 419, 375

Hartley, M. 1984, IAU Circ. 4015, 1

Lisse, C. M., Fernández, Y. R., Kundu, A. et al. 1999, Icarus 140, 189

Lisse, C. M., Fernández, Y. R., Reach, W. T. et al. 2009, PASP (in Press)

Morris, C. S. 1973, PASP 85, 470

Sanzovo, G. C., Singh, P. D., \& Huebner, W. F. 1996, A\&SAS 120, 301 
Sanzovo, G. C., de Almeida, A. A., Misra, A. et al. 2001, MNRAS 326, 852

Schleicher, D. G., Millis, R. L., Osip, D. J. et al. 1991, Icarus 94, 511.

Tancredi, G., Fernandez, J. A., Rickman, H. et al. 2000, A\&AS 146, 73

Trevisan Sanzovo, D. T. 2006, MSc Thesis, State University of Londrina, Londrina, PR, Brazil

Weaver, H. A., Feldman, P. D., A'Hearn, M. F. et al. 1997, Science 275, 1900 